\title{
Review Article \\ The Complex Role of STAT3 in Viral Infections
}

\author{
Suresh V. Kuchipudi \\ School of Veterinary Medicine and Science, University of Nottingham, Sutton Bonington LE12 5RD, UK \\ Correspondence should be addressed to Suresh V. Kuchipudi; suresh.kuchipudi@nottingham.ac.uk \\ Received 1 April 2015; Accepted 10 June 2015 \\ Academic Editor: Nejat K. Egilmez \\ Copyright (c) 2015 Suresh V. Kuchipudi. This is an open access article distributed under the Creative Commons Attribution License, \\ which permits unrestricted use, distribution, and reproduction in any medium, provided the original work is properly cited. \\ Signal transducer and activators of transcription-3 (STAT3) regulates diverse biological functions including cell growth, \\ differentiation, and apoptosis. In addition, STAT3 plays a key role in regulating host immune and inflammatory responses and \\ in the pathogenesis of many cancers. Several studies reported differential regulation of STAT3 in a range of viral infections. \\ Interestingly, STAT3 appears to direct seemingly contradictory responses and both pro- and antiviral roles of STAT3 have been \\ described. This review summarized the currently known functions of STAT3 in the regulation of viral replication and pathogenesis \\ of viral infections. Some of the key unanswered questions and the gap in our current understanding of the role of STAT3 in viral \\ pathogenesis are discussed.
}

\section{Introduction}

Signal transducers and activators of transcription (STATs) are a family of transcription factors that play crucial roles in regulating a number of diverse biological functions including cell proliferation, differentiation, apoptosis, inflammatory response, immunity, and angiogenesis [1]. There are seven STAT proteins (STATs $1,2,3,4,5 \mathrm{a}, 5 \mathrm{~b}$, and 6 ), which are activated by the signals from cytokine and growth factor receptors in the plasma membrane and regulate gene transcription [2]. A unique feature of STAT proteins is their dual roles, which include signal transduction through the cytoplasm and functioning as transcription factors in the nucleus [3-5].

STATs were first discovered through their capacity to mediate signalling from interferon (IFN) and interleukin6 (IL-6) receptors following binding of cytokines [3, 4, 68]. Each STAT family protein responds to a defined set of cytokines (Table 1), and certain cytokines can activate more than one STAT protein [9]. Cytokine receptors on plasma membrane do not usually possess intrinsic tyrosine kinase activity and their engagement activates receptor-associated tyrosine kinases, prominent of which are Janus kinase (JAK) family kinases (JAK1, JAK2, JAK3, and TYK2) [3, 4, 8-10].

STAT proteins are activated by phosphorylation of specific tyrosine residues, following which they form stable homodimers or heterodimers with other STAT proteins through reciprocal phosphotyrosine-SRC homology 2 (SH2) domain interactions [9]. STAT dimers then translocate to nucleus where they regulate the transcription of a set of specific genes. A number of the downstream target genes of STATs encode cytokines and growth factors, which in turn mediate autocrine and paracrine STAT activation [9].

\section{Noncanonical STAT Activation}

In addition to the canonical model of JAK/STAT signalling, STATs also form dimers in the absence of the activating tyrosine phosphorylation [11]. In the noncanonical model, unphosphorylated STATs are consistently found as a result of constant nuclear import and export. These unphosphorylated nuclear STAT molecules might also contribute to gene regulation [12].

\section{STAT3}

Of all the STAT family proteins, STAT3 is unique as it is known to direct seemingly contradictory responses [13] and is essential for early embryonic development in mice [14]. STAT3 regulates cell-cycle progression and apoptosis, plays a key role in oncogenesis [15], and is aberrantly expressed in cancer cells [16]. STAT3 function has been extensively 
TABLE 1: Activators of STAT family proteins (adapted from Yu et al., 2009 [9]).

\begin{tabular}{ll}
\hline STAT protein & Key activators \\
\hline STAT1 & IFN $\gamma$, IFN $\alpha$, and IFN $\beta$ \\
STAT2 & IFN $\alpha$ and IFN $\beta$ \\
STAT3 & IL-6, IL-10, IL-23, IL-21, IL-11, LIF, and OSM \\
STAT4 & IL-12 \\
STAT5A and & IL-2, GM-CSF, IL-15, IL-7, IL-3, IL-5, growth \\
STAT5B & hormones, and prolactin \\
STAT6 & IL-4 and IL-13 \\
\hline
\end{tabular}

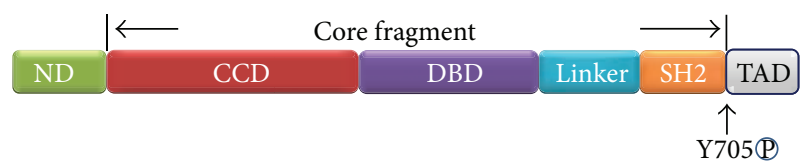

FIGURE 1: Structure of STAT3. The six domains of STAT3 are Nterminal domain (ND), coiled-coil domain (CCD), DNA-binding domain (DBD), linker domain, $\mathrm{SH} 2$ domain, and transcriptional activation domain (TAD). Between $\mathrm{SH} 2$ and TAD there is a tail segment that contains the phosphorylation site Y705.

studied in cell culture systems. STAT3 is known to regulate a number of distinct responses in different cells, including induction of an acute-phase response in hepatoma cells, stimulation of proliferation in B lymphocytes, activation of terminal differentiation and growth arrest in monocytes [4], and maintenance of the pluripotency of embryonic stem cells $[13,17-20]$. The seemingly contradictory responses of STAT3 could be explained in part by the activation of distinct sets of target gene by STAT3 in different cells [21].

\section{STAT3 Domain Structure}

The structure of STAT3 is similar to the other STAT family members comprising six structural regions, namely, $\mathrm{N}$ terminal domain (ND), coiled-coil domain (CCD), DNAbinding domain (DBD), linker domain, $\mathrm{SH} 2$ domain, and a C-terminal transcriptional activation domain (TAD) (Figure 1). The core fragment of STAT3 comprising CCD, $\mathrm{DBD}$, linker, and $\mathrm{SH} 2$ domains is monomeric and the dimer interface observed in the unphosphorylated STAT1 core fragment structure is absent in the STAT3 structure [22].

\section{STAT3 Activation}

STAT3 is activated by phosphorylation at tyrosine 705 in the C-terminal domain [2] and more than 40 different polypeptide ligands are known to cause STAT3 phosphorylation [16]. STAT3 was initially described as a DNA-binding factor that is capable of selectively interacting with an enhancer element in the promoter region of acute-phase genes in interleukin6 (IL-6) stimulated hepatocytes [7]. Subsequently, it became evident that STAT3 can be activated by the entire IL- 6 family and other cytokines including leukemia inhibitory factor (LIF), cardiotrophin-1, ciliary neurotrophic factor (CNTF),
IL-5, IL-9, IL-10, IL-11, IL-12, IL-21, IL-22, IL-27, IFN- $\gamma$, TNF- $\alpha$, LIGHT, a member of the TNF superfamily, monocyte chemotactic protein-1 (MCP-1), macrophage inflammatory protein-1 $\alpha$ (MIP-1 $\alpha)$, CCL-5/RANTES, stem cell factor (SCF), and oncostatin M (OSM) [23-38].

Various growth factor receptors also activate STAT3, which include epidermal growth factor receptors (EGFRs), hepatocyte growth factor receptors (HGFRs), fibroblast growth factor receptors (FGFRs), platelet-derived growth factor receptors (PDGFRs), insulin-like growth factor receptors (IGFRs), and vascular endothelial growth factor receptors (VEGFRs) [39]. In addition, many carcinogenic agents such as nicotine in cigarette smoke, diesel exhaust particles, bacterial lipopolysaccharide (LPS), environmental stress including ultraviolet light, osmotic shock, heat shock, and oxidative stress, $\mathrm{Ca}^{2+} /$ calmodulin-dependent protein kinase II $\gamma$ $(\mathrm{CaMKII} \gamma)$, bile acids, leptin and low $\mathrm{pH}$, black soy peptides, diazoxide, isoliquiritigenin, and olanzapine have been found to activate STAT3 (reviewed by Siveen et al., 2014 [16]).

\section{STAT3 Signal Transduction}

Growth factor or cytokine receptor-ligand interaction results in dimerization of gp130, a signal transducer protein in cytoplasm [40]. This is followed by phosphorylation of JAK family of tyrosine kinases especially JAK1 which in turn mediates STAT3 phosphorylation [21]. STAT3 has two important phosphorylation sites at Tyr705 and Ser727. Ser727 phosphorylation has been considered to be a secondary event after Tyr705 phosphorylation. However, recent evidence suggests that Ser727 phosphorylation on STAT3 is not necessarily a secondary event after Tyr705 phosphorylation but has a role in the regulation of cell survival activity and nuclear translocation of STAT3 in melanocytic cells [41]. Further, STAT3 phosphorylation at serine 727 in the C-terminal transactivation domain promotes maximal transcriptional activation of a subset of target genes [42]. Furthermore, Ser727 phosphorylation of STAT3 appears to be important in tumorigenicity. For example, in glioma, reduced STAT3 Ser727 phosphorylation enhances tumorigenicity which may be regulated in part by CK2-PP2A pathway [43].

The phosphorylation of STAT3 promotes homodimerization, wherein the SH2 domain of each STAT3 monomer interacts with the Y705 residue on another monomeric STAT3 [2]. STAT3 homodimers translocate into the nucleus which is mediated by importin $\alpha 5 / \mathrm{NPI}-1$ [44] and bind to specific DNA response elements such as the IFN-stimulated response element (ISRE) in the promoter regions of responsive target genes and regulate their transcription [45-47] (Figure 2).

STAT3 dimers recognize an 8- to 10-base pair inverted repeat DNA element with a consensus sequence of 5TT(N)AA-3 [15]. Further, nonphosphorylated STAT3 monomers are also capable of dimerization and induction of transcription through binding to NFkappaB [48].

\section{Regulation of STAT3 Activation}

Activation of JAK/STAT pathway begins with the binding of extracellular signalling proteins (ESPs) to specific receptors 


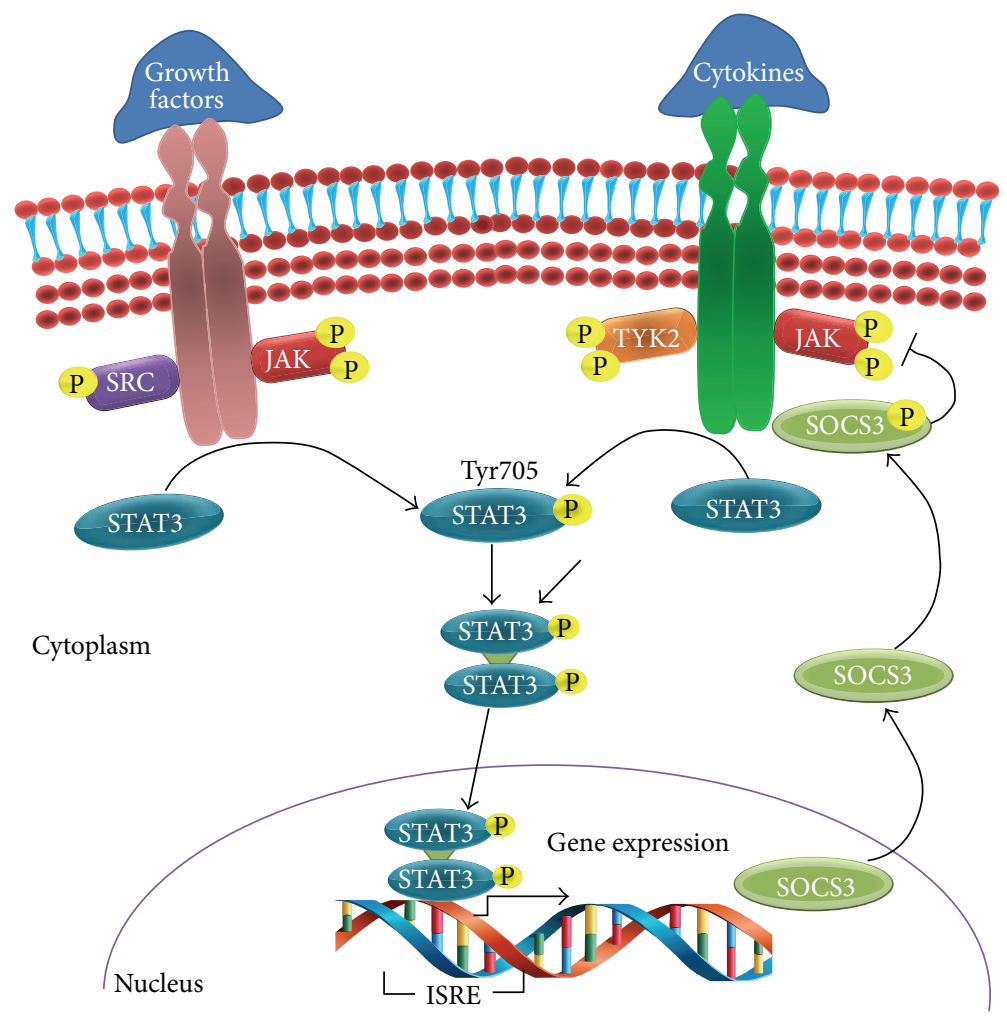

FIGURE 2: STAT3 signal transduction pathway. In response to cytokines and growth factors, STAT3 is phosphorylated by receptor-associated kinases and then forms homo- or heterodimers. STAT3 dimers then translocate to the nucleus where they act as a transcription activator and mediate the expression of a variety of genes. STAT3 activates the transcription of suppressors of cytokine signalling 3 (SOCS3) which act as classical feedback inhibitor of STAT3 activation.

associated with JAKs. Activated JAKs then activate STAT proteins by phosphorylation which otherwise remain latent in the cytoplasmic $[49,50]$. A range of endogenous protein regulators tightly control the receptor-induced STAT3 activation $[4,51-53]$. Several protein tyrosine phosphatases (PTPs) including SHP-2, PTP1B, PTP 2 C, TC45, and SHP-1 have been implicated in the termination of STAT3 signaling. Because only STAT3 dimers bind to DNA, the nuclear PTP TC45 may be important in the termination of STAT3-mediated transcriptional activation [51,53].

Protein inhibitors of activated STAT (PIAS) family members are involved in blocking the DNA-binding ability of STAT proteins thereby inhibiting their function as transcription factors. PIAS family of proteins shares a highly conserved domain structure comprising the $\mathrm{N}$ terminus SAP domain that can bind to AT-rich DNA sequences and a Pro-Ile-Asn-Ile-The (PINIT) motif, which is involved in the nuclear retention of PIAS proteins. PIAS3 has been shown to specifically bind to STAT3 and block its DNA-binding activity and transcriptional activation $[2,52,54]$.

The family of suppressors of cytokine signalling (SOCS) acts as classical feedback inhibitors of the JAK/STAT pathway. STAT3 activates the transcription of SOCS3 which can block STAT3 signalling either by direct binding and inhibition of JAKs, by competing with STAT3 for pY-binding sites on activated receptor chains, or by binding signalling proteins and targeting them for proteasomal degradation $[55,56]$ (Figure 2).

\section{Role of STAT3 in Regulating Cytokine Response}

STAT3 is a signaling mediator of IL-6 and IL-10 family members and other cytokines such as leptin and G-CSF [13, 57]. N-terminal domain of STAT3 negatively regulates type 1 interferon (IFN) response in mice, which is independent of its function as a transcriptional factor [58]. While STAT1 and STAT2 mediate antiviral and inflammatory effects of type I IFNs, STAT3 has been shown to negatively regulate the inflammatory properties of type I IFNs possibly through suppression of STAT1 function [59].

STAT3 activation results in either activation or suppression of inflammatory response depending on the physiological status of the cells. STAT3 is found to be constitutively activated in cancer cells and the persistent activation of STAT3 in cancer cells mediates tumour-promoting inflammation [9]. STAT3 also promotes a potent anti-inflammatory response (AIR); for example, Toxoplasma gondii exploits host STAT3 to prevent LPS-triggered proinflammatory cytokine production in infected mouse macrophages [60]. IL-10 regulates both acute and chronic inflammation [61] and STAT3 is essential for all known aspects of the IL-10-regulated 


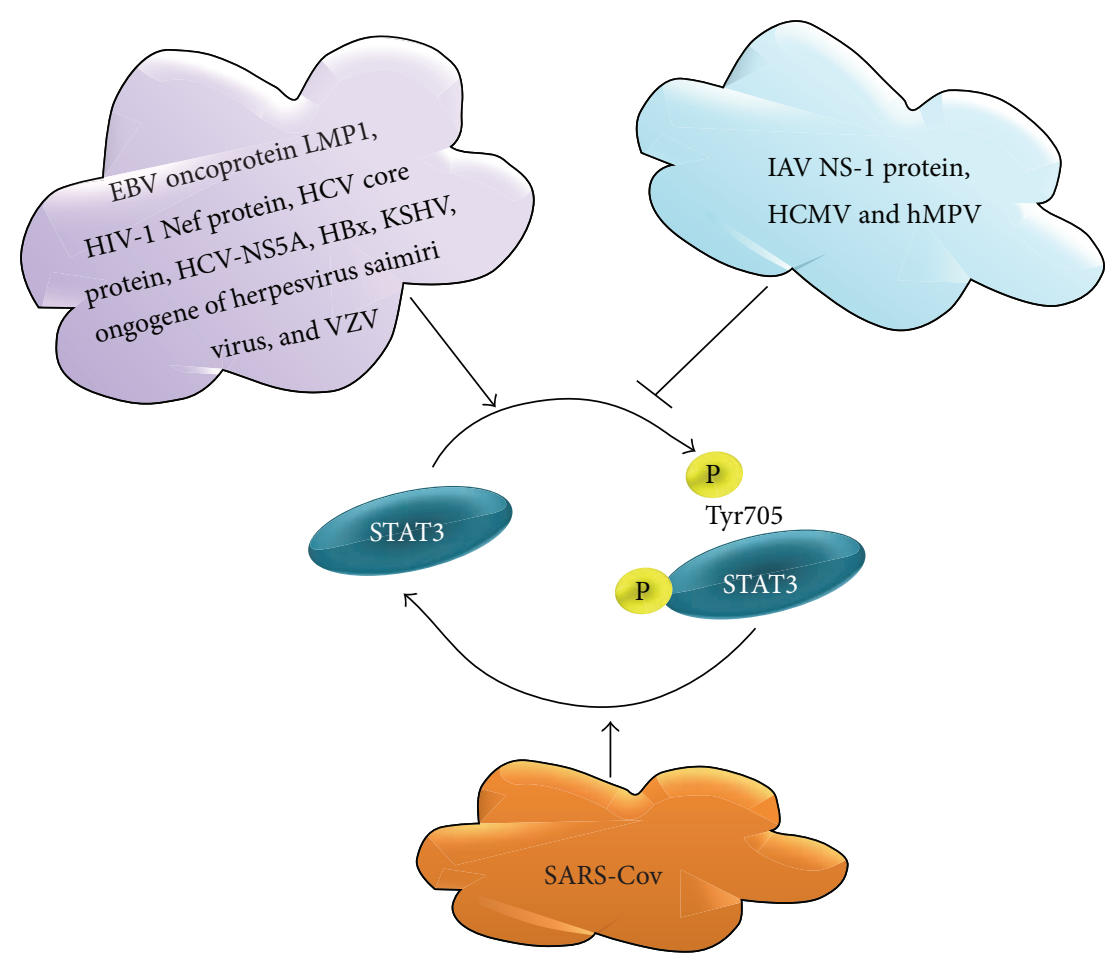

FIGURE 3: STAT3 regulation in viral infections. Epstein-Barr virus (EBV) oncoprotein latent membrane protein 1 (LMP1), human immunodeficiency virus type 1 (HIV-1) Nef protein, hepatitis C virus (HCV) core protein, HCV nonstructural protein 5A (NS5A), hepatitis B virus X protein (HBx), Kaposi's sarcoma-associated herpesvirus (KSHV), saimiri transforming protein (STP) oncogene of Herpesvirus saimiri subgroup A strain 11 (STP-A11), and Varicella-zoster virus (VZV) activate STAT3 phosphorylation. Influenza A virus (IAV) nonstructural protein 1 (NS-1) human metapneumovirus (hMPV) and human cytomegalovirus (HCMV) inhibit STAT3 phosphorylation. Severe acute respiratory syndrome coronavirus (SARS-CoV) infection results in STAT3 dephosphorylation.

anti-inflammatory effect both in vivo and in vitro [62-64]. While it is not clear how the pro- and anti-inflammatory functions of STAT3 are regulated, possible factors could be the physiological status of the cells and the length of STAT3 activation during a response.

\section{Regulation of STATs by Viruses}

A number of viruses are known to regulate STAT family members including STAT1, STAT2, and STAT3. Epstein-Barr virus infection results in transcriptional activation of STAT1 through latent membrane protein 1 (LMP1) [65]. Dengue virus subverts the IFN response in infected human cells by downregulating STAT2 expression [66].

\section{STAT3 Regulation by Viruses}

Several studies described the involvement of STAT3 in the replication and pathogenesis of viruses in humans and animals. Notably, both pro- and antiviral functions of STAT3 have been documented and its precise role in the pathogenesis of viral infections is not yet fully established. A number of DNA and RNA viruses are known to regulate STAT3, which is summarized in Table 2.

STAT3 is either positively or negatively regulated in a range of viral infections depending on the type of virus
TABLE 2: Viruses that are known to regulate STAT3 activation.

\begin{tabular}{|c|c|}
\hline DNA viruses & RNA viruses \\
\hline Epstein-Barr virus (EBV) & $\begin{array}{l}\text { Human immunodeficiency virus } \\
\text { type } 1 \text { (HIV-1) }\end{array}$ \\
\hline $\begin{array}{l}\text { Kaposi's sarcoma-associated } \\
\text { herpesvirus (KSHV) }\end{array}$ & Hepatitis $\mathrm{C}$ virus (HCV) \\
\hline $\begin{array}{l}\text { Herpesvirus saimiri subgroup } \\
\text { A strain } 11 \text { (STP-A11) }\end{array}$ & Influenza A virus (IAV) \\
\hline Varicella-zoster virus (VZV) & $\begin{array}{l}\text { Severe acute respiratory } \\
\text { syndrome coronavirus } \\
\text { (SARS-CoV) }\end{array}$ \\
\hline $\begin{array}{l}\text { Human cytomegalovirus } \\
(\mathrm{HCMV})\end{array}$ & Mumps virus \\
\hline Hepatitis B virus (HBV) & Measles virus \\
\hline
\end{tabular}

involved. Figure 3 provides a summary of positive or negative regulation of STAT3 by viruses. A number of viral proteins interact with STAT3 resulting in the phosphorylation activation. Epstein-Barr virus (EBV) oncoprotein latent membrane protein 1 (LMP1) [67], human immunodeficiency virus type 1 (HIV-1) Nef protein [68], hepatitis C virus (HCV) core protein [69], HCV nonstructural protein 5A (NS5A) [70], mitochondrially associated hepatitis B virus $\mathrm{X}$ protein $(\mathrm{HBx})$ [71], Kaposi's sarcoma-associated herpesvirus (KSHV) [72], 
saimiri transforming protein (STP) oncogene of Herpesvirus saimiri subgroup A strain 11 (STP-A11) [73], and Varicellazoster virus (VZV) [74] promote STAT3 phosphorylation in infected cells.

In contrast, influenza A virus (IAV) nonstructural protein 1 (NS-1) [75] and human metapneumovirus [76] impede STAT3 phosphorylation in infected cells. However, human cytomegalovirus (HCMV) infection inhibits STAT3 phosphorylation but rapidly promotes nuclear localization of unphosphorylated STAT3 to the nucleus and disrupts IL6-induced gene expression [77]. Severe acute respiratory syndrome coronavirus (SARS-CoV) infection of Vero E6 cells results in STAT3 dephosphorylation at Tyr705 [78]. In addition HCV promotes STAT3 ubiquitination and degradation via the proteasome [79].

\section{Role of STAT3 in Mediating Host Immune Responses to Viruses}

STAT3 plays an important role in adaptive immune response, in particular in the regulation of T lymphocyte function. STAT3 mediates IL-6-dependent T cell proliferation by preventing apoptosis [80]. Further, STAT3 regulates proliferation, survival, and differentiation of $\mathrm{CD}^{+}{ }^{-}[81]$ and $\mathrm{CD}^{+}{ }^{-}$ cells [82]. Furthermore, STAT3 is essential in upregulating $\mathrm{CD}^{+} \mathrm{T}$ cell-mediated responses to viruses. For example, STAT3 plays an important role in the activation of $\mathrm{CD}^{+} \mathrm{T}$ cells effective response during herpes simplex virus (HSV-1) infection [82].

It is evident that viruses either promote or disrupt STAT3mediated gene transcription and host immune responses against viruses. Further, activation or inhibition of STAT3mediated signalling appears to be dependent on virus and host cell type involved. Inhibition of STAT3 activation could be a strategy of viruses to subvert host immune responses. On the other hand STAT3-mediated gene transcription of proviral factors could be essential for certain other viruses. It is possible that the timing of STAT3 regulation during virus infection may be critical and hence require further in depth studies to profile STAT3 regulation during different stages of viral infection.

\section{Role of STAT3 in Virus Replication}

The role of STAT3 in virus replication appears to be complex, as it appears to function as a proviral factor in some viral infections and antiviral factor in others. STAT3 cooperatively interacts with hepatocyte nuclear factor 3 (HNF-3) and activates hepatitis B virus (HBV) gene expression [83]. There is a STAT3 binding site within the core domain of hepatitis B virus (HBV) enhancer 1. IL-6 and epidermal growth factor stimulates the interaction of HBV enhancer 1 DNA-STAT3 protein resulting in overall stimulation of $\mathrm{HBV}$ enhancer 1 function and viral gene expression [83].

HCV constitutively activates STAT3 in liver cells which plays an important role in HCV RNA replication [84]. HCV replicon-expressing cells showed constitutive activation of STAT3 which is mediated by oxidative stress and influenced by the activation of cellular kinases, including p38 mitogenactivated protein kinase, JNK, JAK-2, and Src [84].

HCMV primarily utilizes unphosphorylated STAT3 to promote, either directly or indirectly, the initiation of HCMV DNA replication [77]. HCMV infection disrupts IL-6 induced phosphorylation of STAT3 and expression of a subset of IL-6-induced STAT3-regulated genes including SOCS3. HCMV $72-\mathrm{kDa}$ immediate-early 1 (IE1) protein associates with STAT3 and rapidly promotes nuclear localization of STAT3 in the absence of robust phosphorylation at Y705 and inhibition of STAT3 nuclear localization or STAT3 expression during infection results in diminished HCMV genome replication [77].

STAT3 activation was shown to be critical for replication of VZV that causes varicella (chickenpox) during primary infection and zoster (shingles) upon reactivation [74]. VZV triggers STAT3 phosphorylation in cells infected in vitro and also in human skin xenografts in SCID mice in vivo. STAT3 activation induces the antiapoptotic protein survivin and both STAT3 and surviving are essential for VZV replication as inhibition of STAT3 phosphorylation and survivin results in restricted VZV replication [74].

Mumps virus $V$ protein functions as a ubiquitin ligase that targets STAT3 for degradation and STAT3 evasion has been proposed to be beneficial to the replication of Paramyxoviruses [85]. Further, mumps virus $\mathrm{V}$ protein prevents responses to interleukin- 6 and $\mathrm{v}$-Src signals and can induce apoptosis in STAT3-dependent multiple myeloma cells and transformed murine fibroblasts $[85,86]$. In a similar fashion, measles virus also interferes with STAT3 activation and it was proposed that this could provide several general or tissuespecific replication advantages to the virus [86].

Influenza A virus (IAV) NS1 protein interferes with IFN production [87] which correlates to reduced phosphorylation of STAT3. Transfection of NS1 from a highly pathogenic avian influenza (HPAI) H5N1 virus in human lung epithelial A549 cells resulted in a notable reduction in IFN-inducible STAT3 phosphorylation [75].

Viruses such as HBV, HCV, and HCMV appear to exploit host genes transcriptionally regulated by STAT3 for their gene replication which could be independent of the regulatory effects of STAT3 on type 1 IFN response. Whereas STAT3 inhibition appears to be a strategy of viruses such as Paramyxo- and Orthomyxoviruses to evade host innate and adaptive immune responses, it is plausible that inhibition of STAT3 signalling could provide a much broader spectrum of cytokine and growth factor suppression to allow replication and spread of these viruses in vivo.

\section{Role of STAT3 in the Pathogenesis of Viral Infections}

STAT3 role in viral pathogenesis appears to be complex with reports suggesting both promotion of innate antiviral response and contribution to the detrimental effects of viral infection. STAT3 is constitutively phosphorylated in neoplastic cells [88] and many viruses exploit the oncogenic effects of phosphorylated STAT3 (pSTAT3). STAT3 plays a central role in the pathogenesis of oncogenic viruses such 
as the $\gamma$-herpesviruses, KSHV, EBV, and Herpesvirus saimiri $[72,73,89]$.

STAT3 role has been well characterized in the pathogenesis of viral infections resulting in liver disease in humans. HCV infection in liver cells causes constitutive activation of STAT3, which plays a central role in chronic hepatitis and often results in liver cirrhosis and hepatocellular carcinoma [84]. HCV core protein directly interacts with and activates STAT3 through phosphorylation of the critical tyrosine and is responsible for the virus-induced transformation. Activation of STAT3 by the HCV core results in rapid proliferation and upregulation of Bcl-XL and cyclin-D1 and additional expression of STAT3 in HCV core-expressing cells results in anchorage-independent growth and tumorigenesis [90]. Cytokine stimulation of HBV gene expression represents an important regulatory scheme of direct relevance to the pathogenesis of liver disease associated with HBV infection [83]. HCMV infection of PHH and HepG2 cells results in activation of the IL-6-JAK-STAT3 pathway which results in the transformation of PHH cells and enhanced HepG2 tumorsphere formation raising the possibility that HCMV infection might be involved in the genesis of hepatocellular carcinoma [91].

STAT3 activation and upregulation of antiapoptotic protein survivin play an important role in the pathogenesis of lytic as well as tumorigenic herpesviruses [74]. STAT3 and survivin have been shown to play a major role in the malignant transformation of cells infected by $\gamma$-herpesviruses, such as KSHV [72]. STAT3 activation is essential for the skin infections caused by VZV which is necessary for viral transmission and persistence in the human population [74].

\section{Protective Role of STAT3 in Viral Diseases}

STAT3 is also known to promote host defense against virus infections and play a protective role in regulating virus mediated proinflammation. Gp130-STAT3 signalling plays an important role in the innate immune response in cardiac myocytes against coxsackievirus B3 infection [92]. Dysregulation of host proinflammatory response is a key contributing factor to the morbidity and mortality of virulent influenza virus infections such as the highly pathogenic avian influenza (HPAI) H5N1 viruses [93-96]. We recently showed that elevated proinflammatory response in chickens is a major pathogenicity factor of HPAI-H5N1 virus infection possibly mediated by inhibition of STAT3 phosphorylation [96]. HPAI-H5N1 virus infection results in STAT3 inhibition and elevated proinflammatory response in chicken cells. In contrast STAT3 inhibition was not found in HPAI-H5N1 virus infected duck cells which show a moderate proinflammatory response.

In summary, STAT3 plays a significant role in the complex interplay between viruses and their hosts and functions as either a pro- or antiviral factor depending on the virus and host cell type involved. While STAT3 role has been reasonably well characterized in the pathogenesis of oncogenic viruses and viruses causing liver pathology, its role in many other viral infections is less well understood. STAT3 regulates antiviral and proinflammatory responses, either through transcriptional regulation of other cellular factors or through pathways independent of its role as a transcription factor. The seemingly contradictory roles of STAT3 in viral infections raise a number of interesting questions: "what factors determine the switch between pro- and anti-inflammatory functions of STAT3?," "how are viruses able to exploit STAT3 signalling for their gene replication?," and "does STAT3 either negatively or positively regulate type 1 IFN response depending on the virus type involved?" Further in depth studies to dissect the role of STAT3 in viral infections could provide valuable insights into viral pathogenesis and development of novel antiviral therapies. In vitro studies using cell culture systems are a valuable tool to dissect the molecular basis of STAT3 role in innate response to viruses. However, in vivo studies are essential to elucidate STAT3 role in adaptive immune response to viruses. Complementary in vitro and in vivo experiments are therefore essential to better understand the seemingly contradictory role of STAT3 in viral infections.

\section{Conflict of Interests}

The author declares that there is no conflict of interests regarding the publication of this paper.

\section{References}

[1] S. A. Duncan, Z. Zhong, Z. Wen, and J. E. Darnell Jr., "STAT signaling is active during early mammalian development," Developmental Dynamics, vol. 208, no. 2, pp. 190-198, 1997.

[2] P. A. Johnston and J. R. Grandis, "STAT3 signaling: anticancer strategies and challenges," Molecular Interventions, vol. 11, no. 1, pp. 18-26, 2011.

[3] J. E. Darnell Jr., I. M. Kerr, and G. R. Stark, "Jak-STAT pathways and transcriptional activation in response to IFNs and other extracellular signaling proteins," Science, vol. 264, no. 5164, pp. 1415-1421, 1994.

[4] P. C. Heinrich, I. Behrmann, G. Müller-Newen, F. Schaper, and L. Graeve, "Interleukin-6-type cytokine signalling through the gp130/Jak/STAT pathway," Biochemical Journal, vol. 334, part 2, pp. 297-314, 1998.

[5] G. R. Stark, I. M. Kerr, B. R. G. Williams, R. H. Silverman, and R. D. Schreiber, "How cells respond to interferons," Annual Review of Biochemistry, vol. 67, pp. 227-264, 1998.

[6] Z. Zhong, Z. Wen, and J. E. Darnell Jr., "Stat3: a STAT family member activated by tyrosine phosphorylation in response to epidermal growth factor and interleukin-6," Science, vol. 264, no. 5155, pp. 95-98, 1994.

[7] S. Akira, Y. Nishio, M. Inoue et al., "Molecular cloning of APRF, a novel IFN-stimulated gene factor 3 p91-related transcription factor involved in the gp130-mediated signaling pathway," Cell, vol. 77, no. 1, pp. 63-71, 1994.

[8] C. Schindler, D. E. Levy, and T. Decker, "JAK-STAT signaling: from interferons to cytokines," The Journal of Biological Chemistry, vol. 282, no. 28, pp. 20059-20063, 2007.

[9] H. Yu, D. Pardoll, and R. Jove, "STATs in cancer inflammation and immunity: a leading role for STAT3," Nature Reviews Cancer, vol. 9, no. 11, pp. 798-809, 2009. 
[10] D. E. Levy and J. E. Darnell Jr., "STATs: transcriptional control and biological impact," Nature Reviews Molecular Cell Biology, vol. 3, no. 9, pp. 651-662, 2002.

[11] A. Mohr, N. Chatain, T. Domoszlai et al., "Dynamics and noncanonical aspects of JAK/STAT signalling," European Journal of Cell Biology, vol. 91, no. 6-7, pp. 524-532, 2012.

[12] W. X. Li, "Canonical and non-canonical JAK-STAT signaling," Trends in Cell Biology, vol. 18, no. 11, pp. 545-551, 2008.

[13] D. E. Levy and C.-K. Lee, "What does Stat3 do?" The Journal of Clinical Investigation, vol. 109, no. 9, pp. 1143-1148, 2002.

[14] K. Takeda, K. Noguchi, W. Shi et al., "Targeted disruption of the mouse Stat 3 gene leads to early embryonic lethality," Proceedings of the National Academy of Sciences of the United States of America, vol. 94, no. 8, pp. 3801-3804, 1997.

[15] A. Subramaniam, M. K. Shanmugam, E. Perumal et al., "Potential role of signal transducer and activator of transcription (STAT)3 signaling pathway in inflammation, survival, proliferation and invasion of hepatocellular carcinoma," Biochimica et Biophysica Acta, vol. 1835, no. 1, pp. 46-60, 2013.

[16] K. S. Siveen, S. Sikka, R. Surana et al., "Targeting the STAT3 signaling pathway in cancer: role of synthetic and natural inhibitors," Biochimica et Biophysica Acta, vol. 1845, no. 2, pp. 136-154, 2014.

[17] H. Boeuf, C. Hauss, F. de Graeve, N. Baran, and C. Kedinger, "Leukemia inhibitory factor-dependent transcriptional activation in embryonic stem cells," The Journal of Cell Biology, vol. 138, no. 6, pp. 1207-1217, 1997.

[18] H. Niwa, T. Burdon, I. Chambers, and A. Smith, "Self-renewal of pluripotent embryonic stem cells is mediated via activation of STAT3," Genes and Development, vol. 12, no. 13, pp. 2048-2060, 1998.

[19] R. Raz, C.-K. Lee, L. A. Cannizzaro, P. D’Eustachio, and D. E. Levy, "Essential role of STAT3 for embryonic stem cell pluripotency," Proceedings of the National Academy of Sciences of the United States of America, vol. 96, no. 6, pp. 2846-2851, 1999.

[20] T. Matsuda, T. Nakamura, K. Nakao et al., "STAT3 activation is sufficient to maintain an undifferentiated state of mouse embryonic stem cells," The EMBO Journal, vol. 18, no. 15, pp. 4261-4269, 1999.

[21] T. Hirano, K. Ishihara, and M. Hibi, "Roles of STAT3 in mediating the cell growth, differentiation and survival signals relayed through the IL-6 family of cytokine receptors," Oncogene, vol. 19, no. 21, pp. 2548-2556, 2000.

[22] Z. Ren, X. Mao, C. Mertens et al., "Crystal structure of unphosphorylated STAT3 core fragment," Biochemical and Biophysical Research Communications, vol. 374, no. 1, pp. 1-5, 2008.

[23] W. M. Peterson, Q. Wang, R. Tzekova, and S. J. Wiegand, "Ciliary neurotrophic factor and stress stimuli activate the JakSTAT pathway in retinal neurons and glia," The Journal of Neuroscience, vol. 20, no. 11, pp. 4081-4090, 2000.

[24] B. A. Stout, M. E. Bates, L. Y. Liu, N. N. Farrington, and P. J. Bertics, "IL-5 and granulocyte-macrophage colony-stimulating factor activate STAT3 and STAT5 and promote Pim-1 and cyclin D3 protein expression in human eosinophils," Journal of Immunology, vol. 173, no. 10, pp. 6409-6417, 2004.

[25] A. Yamasaki, A. Saleh, L. Koussih, S. Muro, A. J. Halayko, and A. S. Gounni, "IL-9 Induces CCL11 expression via STAT3 signalling in human airway smooth muscle cells," PLoS ONE, vol. 5, no. 2, Article ID e9178, 2010.
[26] C. Niemand, A. Nimmesgern, S. Haan et al., "Activation of STAT3 by IL- 6 and IL-10 in primary human macrophages is differentially modulated by suppressor of cytokine signaling 3 ," The Journal of Immunology, vol. 170, no. 6, pp. 3263-3272, 2003.

[27] M. Ernst, M. Najdovska, D. Grail et al., "STAT3 and STAT1 mediate IL-11-dependent and inflammation-associated gastric tumorigenesis in gp130 receptor mutant mice," The Journal of Clinical Investigation, vol. 118, no. 5, pp. 1727-1738, 2008.

[28] N. G. Jacobson, S. J. Szabo, R. M. Weber-Nordt et al., "Interleukin 12 signaling in $\mathrm{T}$ helper type 1 (Th1) cells involves tyrosine phosphorylation of signal transducer and activator of transcription (Stat)3 and Stat4," Journal of Experimental Medicine, vol. 181, no. 5, pp. 1755-1762, 1995.

[29] J. D. Bard, P. Gelebart, M. Anand et al., "IL-21 contributes to JAK3/STAT3 activation and promotes cell growth in ALKpositive anaplastic large cell lymphoma," The American Journal of Pathology, vol. 175, no. 2, pp. 825-834, 2009.

[30] R. Jiang, H. Wang, L. Deng et al., "IL-22 is related to development of human colon cancer by activation of STAT3," BMC Cancer, vol. 13, article 59, 2013.

[31] J. Diegelmann, T. Olszak, B. Göke, R. S. Blumberg, and S. Brand, "A novel role for interleukin-27 (IL-27) as mediator of intestinal epithelial barrier protection mediated via differential signal transducer and activator of transcription (STAT) protein signaling and induction of antibacterial and anti-inflammatory proteins," The Journal of Biological Chemistry, vol. 287, no. 1, pp. 286-298, 2012.

[32] T. Kordula, M. Bugno, J. Goldstein, and J. Travis, "Activation of signal transducer and activator of transcription-3 (stat3) expression by interferon-gamma and interleukin-6 in hepatoma cells," Biochemical and Biophysical Research Communications, vol. 216, no. 3, pp. 999-1005, 1995.

[33] S. Miscia, M. Marchisio, A. Grilli et al., “Tumor necrosis factor alpha (TNF-alpha) activates Jak1/Stat3-Stat5b signaling through TNFR-1 in human B cells," Cell Growth and Differentiation, vol. 13, no. 1, pp. 13-18, 2002.

[34] N. Nadiminty, J. Y. Chun, Y. Hu, S. Dutt, X. Lin, and A. C. Gao, "LIGHT, a member of the TNF superfamily, activates Stat3 mediated by NIK pathway," Biochemical and Biophysical Research Communications, vol. 359, no. 2, pp. 379-384, 2007.

[35] M. Mellado, J. M. Rodríguez-Frade, A. Aragay et al., "The chemokine monocyte chemotactic protein 1 triggers Janus kinase 2 activation and tyrosine phosphorylation of the CCR2B receptor," The Journal of Immunology, vol. 161, no. 2, pp. 805-813, 1998.

[36] M. Wong and E. N. Fish, "RANTES and MIP-1alpha activate Stats in T cells," The Journal of Biological Chemistry, vol. 273, no. 1, pp. 309-314, 1998.

[37] A. Gotoh, H. Takahira, C. Mantel, S. Litz-Jackson, H. S. Boswell, and H. E. Broxmeyer, "Steel factor induces serine phosphorylation of Stat3 in human growth factor-dependent myeloid cell lines," Blood, vol. 88, no. 1, pp. 138-145, 1996.

[38] S. L. Fossey, M. D. Bear, W. C. Kisseberth, M. Pennell, and C. A. London, "Oncostatin M promotes STAT3 activation, VEGF production, and invasion in osteosarcoma cell lines," BMC Cancer, vol. 11, article 125, 2011.

[39] B. Debnath, S. Xu, and N. Neamati, "Small molecule inhibitors of signal transducer and activator of transcription 3 (stat3) protein," Journal of Medicinal Chemistry, vol. 55, no. 15, pp. 6645-6648, 2012.

[40] H. Wang, F. Lafdil, X. Kong, and B. Gao, "Signal transducer and activator of transcription 3 in liver diseases: a novel therapeutic 
target," International Journal of Biological Sciences, vol. 7, no. 5, pp. 536-550, 2011.

[41] M. Sakaguchi, M. Oka, T. Iwasaki, Y. Fukami, and C. Nishigori, "Role and regulation of STAT3 phosphorylation at Ser727 in melanocytes and melanoma cells," Journal of Investigative Dermatology, vol. 132, no. 7, pp. 1877-1885, 2012.

[42] D. A. Frank, "STAT3 as a central mediator of neoplastic cellular transformation," Cancer Letters, vol. 251, no. 2, pp. 199-210, 2007.

[43] T. Mandal, A. Bhowmik, A. Chatterjee, U. Chatterjee, S. Chatterjee, and M. K. Ghosh, "Reduced phosphorylation of Stat3 at Ser-727 mediated by casein kinase 2-protein phosphatase 2A enhances Stat3 Tyr-705 induced tumorigenic potential of glioma cells," Cellular Signalling, vol. 26, no. 8, pp. 1725-1734, 2014.

[44] J. Ma and X. Cao, "Regulation of Stat3 nuclear import by importin $\alpha 5$ and importin $\alpha 7$ via two different functional sequence elements," Cellular Signalling, vol. 18, no. 8, pp. 11171126, 2006.

[45] P. Weerasinghe, Y. Li, Y. Guan, R. Zhang, D. J. Tweardy, and N. Jing, "T40214/PEI complex: a potent therapeutics for prostate cancer that targets STAT3 signaling," Prostate, vol. 68, no. 13, pp. 1430-1442, 2008.

[46] V. C. de Araújo, C. Furuse, P. R. Cury, A. Altemani, and N. S. de Araújo, "STAT3 expression in salivary gland tumours," Oral Oncology, vol. 44, no. 5, pp. 439-445, 2008.

[47] S.-H. Chen, D. A. Murphy, W. Lassoued, G. Thurston, M. D. Feldman, and W. M. F. Lee, "Activated STAT3 is a mediator and biomarker of VEGF endothelial activation," Cancer Biology and Therapy, vol. 7, no. 12, pp. 1994-2003, 2008.

[48] J. Yang, X. Liao, M. K. Agarwal, L. Barnes, P. E. Auron, and G. R. Stark, "Unphosphorylated STAT3 accumulates in response to IL- 6 and activates transcription by binding to NFאBB," Genes and Development, vol. 21, no. 11, pp. 1396-1408, 2007.

[49] K. Shual, A. Ziemiecki, A. F. Wilks et al., "Polypeptide signalling to the nucleus through tyrosine phosphorylation of Jak and Stat proteins," Nature, vol. 366, no. 6455, pp. 580-583, 1993.

[50] C. Schindler, K. Shuai, V. R. Prezioso, and J. E. Darnell Jr., "Interferon-dependent tyrosine phosphorylation of a latent cytoplasmic transcription factor," Science, vol. 257, no. 5071, pp. 809-813, 1992.

[51] P. C. Heinrich, I. Behrmann, S. Haan, H. M. Hermanns, G. Müller-Newen, and F. Schaper, "Principles of interleukin (IL)-6-type cytokine signalling and its regulation," Biochemical Journal, vol. 374, no. 1, pp. 1-20, 2003.

[52] S. Wormald and D. J. Hilton, "Inhibitors of cytokine signal transduction," The Journal of Biological Chemistry, vol. 279, no. 2, pp. 821-824, 2004.

[53] A. Herrmann, M. Vogt, M. Mönnigmann et al., "Nucleocytoplasmic shuttling of persistently activated STAT3," Journal of Cell Science, vol. 120, part 18, pp. 3249-3261, 2007.

[54] K. Shuai, "Regulation of cytokine signaling pathways by PIAS proteins," Cell Research, vol. 16, no. 2, pp. 196-202, 2006.

[55] D. R. Robinson, Y.-M. Wu, S. Kalyana-Sundaram et al., "Identification of recurrent NAB2-STAT6 gene fusions in solitary fibrous tumor by integrative sequencing," Nature Genetics, vol. 45, no. 2, pp. 180-185, 2013.

[56] H. L. M. Koskela, S. Eldfors, P. Ellonen et al., "Somatic STAT3 mutations in large granular lymphocytic leukemia," The New England Journal of Medicine, vol. 366, no. 20, pp. 1905-1913, 2012.
[57] B. B. Aggarwal, A. B. Kunnumakkara, K. B. Harikumar et al., "Signal transducer and activator of transcription-3, inflammation, and cancer: how intimate is the relationship?" Annals of the New York Academy of Sciences, vol. 1171, pp. 59-76, 2009.

[58] W.-B. Wang, D. E. Levy, and C.-K. Lee, "STAT3 negatively regulates type I IFN-mediated antiviral response," Journal of Immunology, vol. 187, no. 5, pp. 2578-2585, 2011.

[59] H. H. Ho and L. B. Ivashkiv, "Role of STAT3 in type I interferon responses: negative regulation of STAT1-dependent inflammatory gene activation," The Journal of Biological Chemistry, vol. 281, no. 20, pp. 14111-14118, 2006.

[60] B. A. Butcher, L. Kim, A. D. Panopoulos, S. S. Watowich, P. J. Murray, and E. Y. Denkers, "Cutting edge: IL-10-independent STAT3 activation by Toxoplasma gondii mediates suppression of IL-12 and TNF- $\alpha$ in host macrophages," The Journal of Immunology, vol. 174, no. 6, pp. 3148-3152, 2005.

[61] L. M. Williams, G. Ricchetti, U. Sarma, T. Smallie, and B. M. J. Foxwell, "Interleukin-10 suppression of myeloid cell activation - A continuing puzzle," Immunology, vol. 113, no. 3, pp. 281-292, 2004.

[62] M. Kobayashi, M.-N. Kweon, H. Kuwata et al., "Toll-like receptor-dependent production of IL-12p40 causes chronic enterocolitis in myeloid cell-specific Stat3-deficient mice," The Journal of Clinical Investigation, vol. 111, no. 9, pp. 1297-1308, 2003.

[63] A. Matsukawa, K. Takeda, S. Kudo, T. Maeda, M. Kagayama, and S. Akira, "Aberrant inflammation and lethality to septic peritonitis in mice lacking STAT3 in macrophages and neutrophils," Journal of Immunology, vol. 171, no. 11, pp. 6198-6205, 2003.

[64] K. C. El Kasmi, J. Holst, M. Coffre et al., "General nature of the STAT3-activated anti-inflammatory response," The Journal of Immunology, vol. 177, no. 11, pp. 7880-7888, 2006.

[65] C. Richardson, C. Fielding, M. Rowe, and P. Brennan, "EpsteinBarr virus regulates STAT1 through latent membrane protein 1," Journal of Virology, vol. 77, no. 7, pp. 4439-4443, 2003.

[66] M. Jones, A. Davidson, L. Hibbert et al., "Dengue virus inhibits alpha interferon signaling by reducing STAT2 expression," Journal of Virology, vol. 79, no. 9, pp. 5414-5420, 2005.

[67] C.-P. Kung, D. G. Meckes Jr., and N. Raab-Traub, “Epstein-barr virus LMP1 activates EGFR, STAT3, and ERK through effects on PKC\&," Journal of Virology, vol. 85, no. 9, pp. 4399-4408, 2011.

[68] Z. Percario, E. Olivetta, G. Fiorucci et al., "Human immunodeficiency virus type 1 (HIV-1) Nef activates STAT3 in primary human monocyte/macrophages through the release of soluble factors: involvement of Nef domains interacting with the cell endocytotic machinery," Journal of Leukocyte Biology, vol. 74, no. 5, pp. 821-832, 2003.

[69] R. S. Tacke, A. Tosello-Trampont, V. Nguyen, D. W. Mullins, and Y.S. Hahn, "Extracellular hepatitis $\mathrm{C}$ virus core protein activates STAT3 in human monocytes/macrophages/dendritic cells via an IL-6 autocrine pathway," The Journal of Biological Chemistry, vol. 286, no. 12, pp. 10847-10855, 2011.

[70] G. Gong, G. Waris, R. Tanveer, and A. Siddiqui, "Human hepatitis C virus NS5A protein alters intracellular calcium levels, induces oxidative stress, and activates STAT-3 and NF$\kappa \mathrm{B}, "$ Proceedings of the National Academy of Sciences of the United States of America, vol. 98, no. 17, pp. 9599-9604, 2001.

[71] G. Waris, K.-W. Huh, and A. Siddiqui, "Mitochondrially associated hepatitis B virus X protein constitutively activates transcription factors STAT-3 and NF-kappa B via oxidative stress," Molecular and Cellular Biology, vol. 21, no. 22, pp. 7721-7730, 2001. 
[72] A. S. Punjabi, P. A. Carroll, L. Chen, and M. Lagunoff, "Persistent activation of STAT3 by latent Kaposi's sarcoma-associated herpesvirus infection of endothelial cells," Journal of Virology, vol. 81, no. 5, pp. 2449-2458, 2007.

[73] Y.-H. Chung, N.-H. Cho, M. I. Garcia, S.-H. Lee, P. Feng, and J. U. Jung, "Activation of Stat 3 transcription factor by Herpesvirus saimiri STP-A oncoprotein," Journal of Virology, vol. 78, no. 12, pp. 6489-6497, 2004.

[74] N. Sen, X. Che, J. Rajamani et al., "Signal transducer and activator of transcription 3 (STAT3) and survivin induction by varicella-zoster virus promote replication and skin pathogenesis," Proceedings of the National Academy of Sciences of the United States of America, vol. 109, no. 2, pp. 600-605, 2012.

[75] D. Jia, R. Rahbar, R. W. Y. Chan et al., "Influenza virus nonstructural protein 1 (NS1) disrupts interferon signaling," PLoS ONE, vol. 5, no. 11, Article ID el3927, 2010.

[76] D. N. Mitzel, R. J. Jaramillo, H. Stout-Delgado, A. P. Senft, and K. S. Harrod, "Human metapneumovirus inhibits the IL-6induced JAK/STAT3 signalling cascade in airway epithelium," Journal of General Virology, vol. 95, part 1, pp. 26-37, 2014.

[77] J. M. Reitsma, H. Sato, M. Nevels, S. S. Terhune, and C. Paulus, "Human cytomegalovirus IE1 protein disrupts interleukin-6 signaling by sequestering STAT3 in the nucleus," Journal of Virology, vol. 87, no. 19, pp. 10763-10776, 2013.

[78] T. Mizutani, S. Fukushi, M. Murakami et al., "Tyrosine dephosphorylation of STAT3 in SARS coronavirus-infected Vero E6 cells," FEBS Letters, vol. 577, no. 1-2, pp. 187-192, 2004.

[79] N. J. Stevenson, N. M. Bourke, E. J. Ryan et al., "Hepatitis C virus targets the interferon- $\alpha$ JAK/STAT pathway by promoting proteasomal degradation in immune cells and hepatocytes," FEBS Letters, vol. 587, no. 10, pp. 1571-1578, 2013.

[80] K. Takeda, T. Kaisho, N. Yoshida, J. Takeda, T. Kishimoto, and S. Akira, "Stat3 activation is responsible for IL-6-dependent $\mathrm{T}$ cell proliferation through preventing apoptosis: generation and characterization of T cell-specific stat3-deficient mice," The Journal of Immunology, vol. 161, no. 9, pp. 4652-4660, 1998.

[81] H.-M. Oh, C.-R. Yu, N. Golestaneh et al., "STAT3 protein promotes T-cell survival and inhibits interleukin-2 production through up-regulation of class $\mathrm{O}$ forkhead transcription factors," Journal of Biological Chemistry, vol. 286, no. 35, pp. 3088830897, 2011.

[82] C.-R. Yu, I. M. Dambuza, Y.-J. Lee, G. M. Frank, and C. E. Egwuagu, "STAT3 regulates proliferation and survival of $\mathrm{CD} 8^{+}$ T cells: enhances effector responses to HSV-1 infection, and inhibits IL- $10^{+}$regulatory $\mathrm{CD} 8^{+} \mathrm{T}$ cells in autoimmune uveitis," Mediators of Inflammation, vol. 2013, Article ID 359674, 10 pages, 2013.

[83] G. Waris and A. Siddiqui, "Interaction between STAT-3 and HNF-3 leads to the activation of liver-specific hepatitis B virus enhancer 1 function," Journal of Virology, vol. 76, no. 6, pp. 2721$2729,2002$.

[84] G. Waris, J. Turkson, T. Hassanein, and A. Siddiqui, "Hepatitis C virus (HCV) constitutively activates STAT-3 via oxidative stress: role of STAT-3 in HCV replication," Journal of Virology, vol. 79, no. 3, pp. 1569-1580, 2005.

[85] C. M. Ulane, J. J. Rodriguez, J.-P. Parisien, and C. M. Horvath, "STAT3 ubiquitylation and degradation by mumps virus suppress cytokine and oncogene signaling," Journal of Virology, vol. 77, no. 11, pp. 6385-6393, 2003.

[86] H. Palosaari, J.-P. Parisien, J. J. Rodriguez, C. M. Ulane, and C. M. Horvath, "STAT protein interference and suppression of cytokine signal transduction by measles virus V protein," Journal of Virology, vol. 77, no. 13, pp. 7635-7644, 2003.

[87] B. G. Hale, R. E. Randall, J. Ortin, and D. Jackson, "The multifunctional NS1 protein of influenza A viruses," Journal of General Virology, vol. 89, no. 10, pp. 2359-2376, 2008.

[88] S. I. Grivennikov and M. Karin, "Dangerous liaisons: STAT3 and NF-kappaB collaboration and crosstalk in cancer," Cytokine and Growth Factor Reviews, vol. 21, no. 1, pp. 11-19, 2010.

[89] Z. Wang, F. Luo, L. Li et al., "STAT3 activation induced by Epstein-Barr virus latent membrane proteinl causes vascular endothelial growth factor expression and cellular invasiveness via JAK3 and ERK signaling," European Journal of Cancer, vol. 46, no. 16, pp. 2996-3006, 2010.

[90] T. Yoshida, T. Hanada, T. Tokuhisa et al., "Activation of STAT3 by the hepatitis $C$ virus core protein leads to cellular transformation," Journal of Experimental Medicine, vol. 196, no. 5, pp. 641-653, 2002.

[91] Q. Lepiller, W. Abbas, A. Kumar, M. K. Tripathy, and G. Herbein, "HCMV activates the IL-6-JAK-STAT3 axis in HepG2 cells and primary human hepatocytes," PLoS ONE, vol. 8, no. 3, Article ID e59591, 2013.

[92] T. Yajima, H. Yasukawa, E.-S. Jeon et al., "Innate defense mechanism against virus infection within the cardiac myocyte requiring gp130-STAT3 signaling," Circulation, vol. 114, no. 22, pp. 2364-2373, 2006.

[93] I. Ramos and A. Fernandez-Sesma, "Innate immunity to H5N1 influenza viruses in humans," Viruses, vol. 4, no. 12, pp. 33633388, 2012.

[94] C. Y. Cheung, L. L. M. Poon, A. S. Lau et al., "Induction of proinflammatory cytokines in human macrophages by influenza $\mathrm{A}$ (H5N1) viruses: a mechanism for the unusual severity of human disease?" The Lancet, vol. 360, no. 9348, pp. 1831-1837, 2002.

[95] A. S. Lipatov, S. Andreansky, R. J. Webby et al., "Pathogenesis of Hong Kong H5N1 influenza virus NS gene reassortants in mice: the role of cytokines and B- and T-cell responses," Journal of General Virology, vol. 86, no. 4, pp. 1121-1130, 2005.

[96] S. V. Kuchipudi, M. Tellabati, S. Sebastian et al., "Highly pathogenic avian influenza virus infection in chickens but not ducks is associated with elevated host immune and proinflammatory responses," Veterinary Research, vol. 45, no. 1, article 118, 2014. 


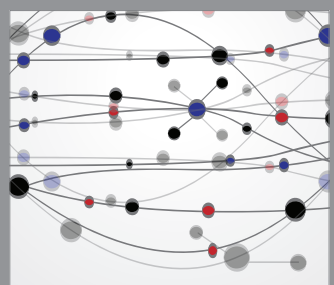

The Scientific World Journal
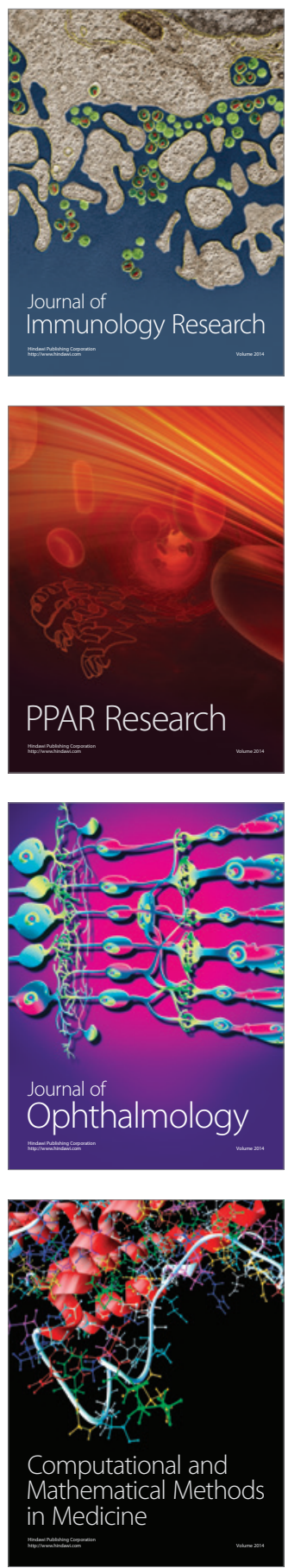

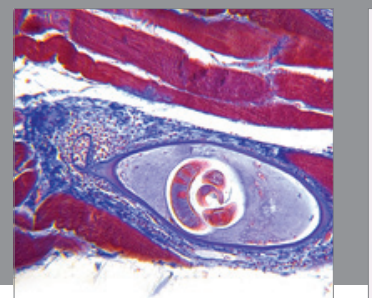

Gastroenterology

Research and Practice
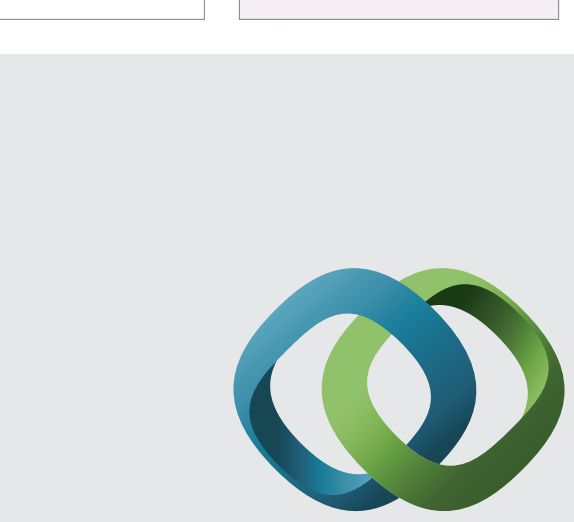

\section{Hindawi}

Submit your manuscripts at

http://www.hindawi.com
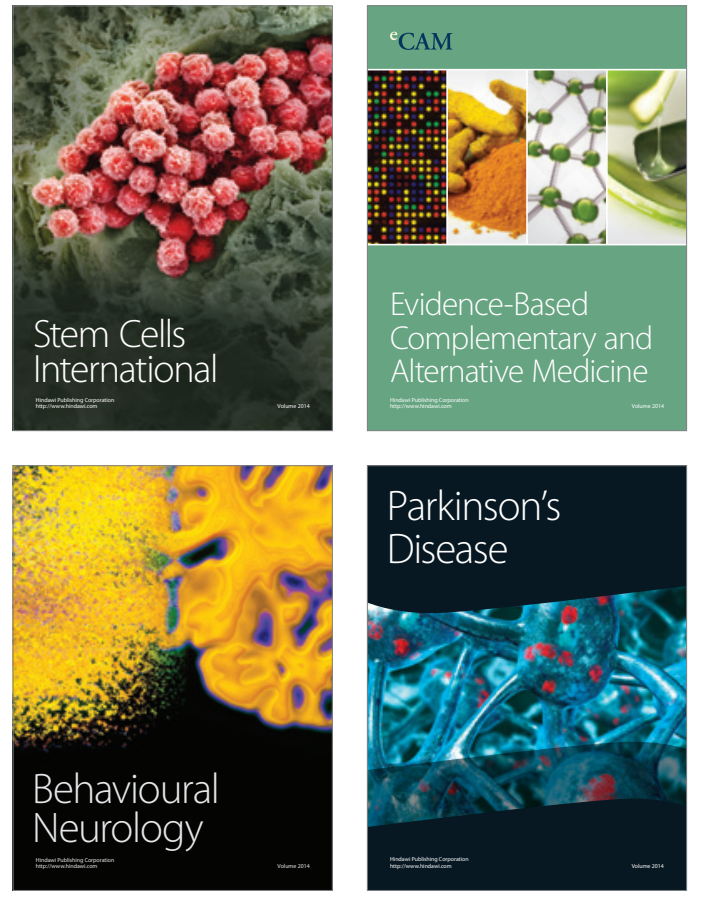
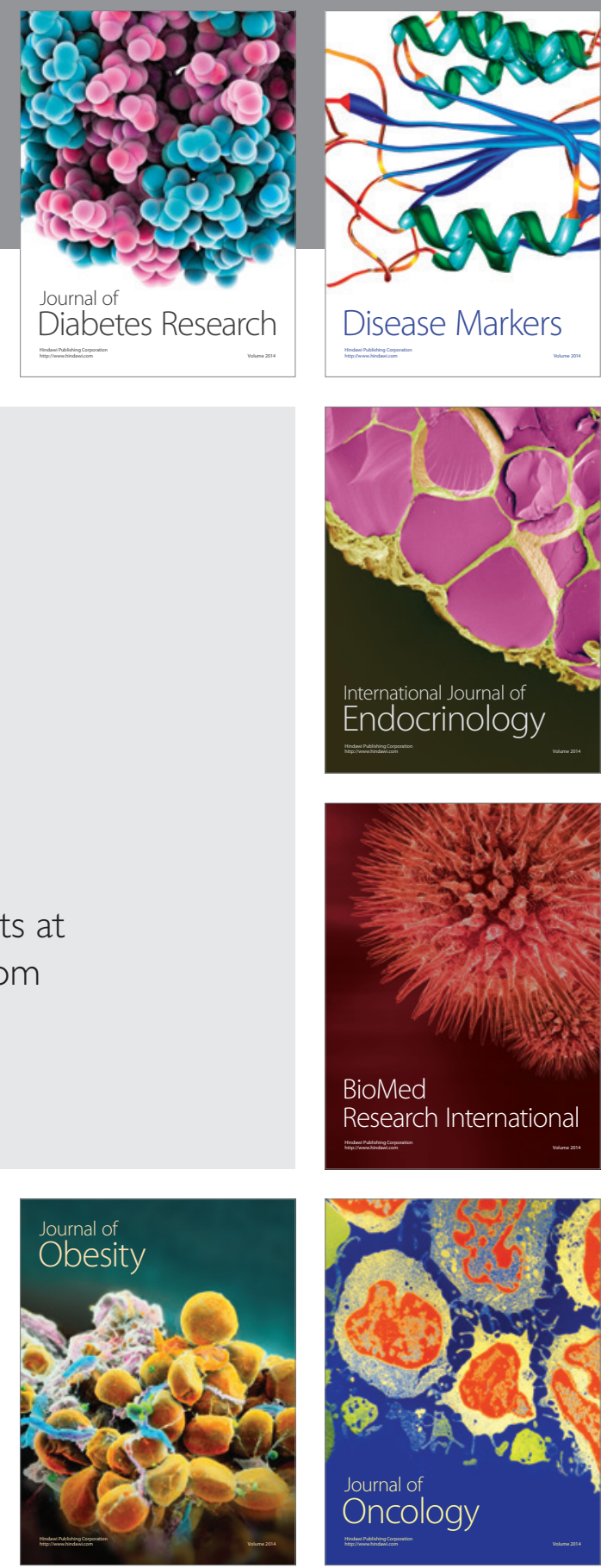

Disease Markers
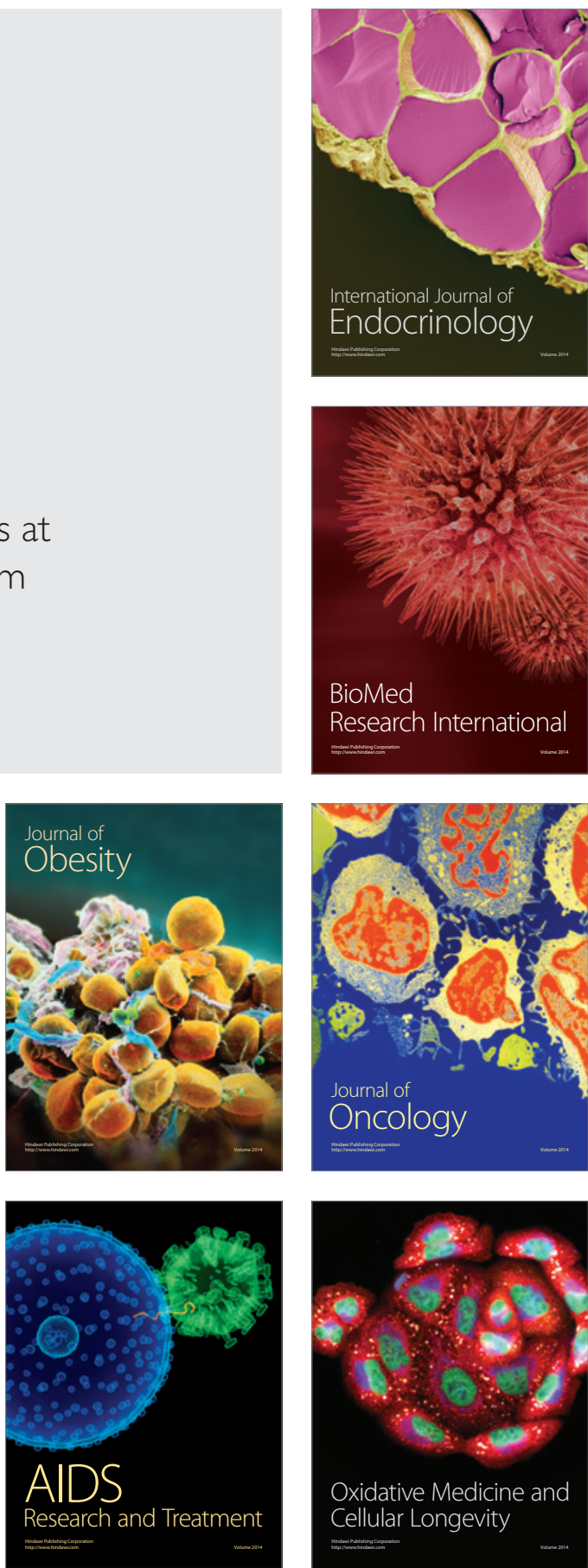